Marketplace is provided as a service to readers using text and images from the manufacturer, supplier or distributor and does not imply endorsement by Vital. Normal and prudent research should be exercised before purchase or use of any product mentioned.

\section{CUTE TOOTH KEEPSAKE}

These beautifully crafted wooden milk tooth holders from Just Wood Toys Ltd have a screwon lid with a sweet face and dangly arms. They are brightly coloured and a great keepsake for those little milk teeth. Imported from Germany, the products are made from reforested wood and all the packaging is environmentally friendly.
They all hold the CE safety mark and are suitable for children aged three years and over. The products have become popular with dental practices either to sell in their reception area, or to give to children as a keepsake after tooth removal. They are offered at $\mathfrak{£} 1.30$ each with free delivery to the practice. If any practice wishes to have a free sample or would like further information just contact Rob Taylor on 01323646575 or email at rob@justwoodtoys.co.uk.

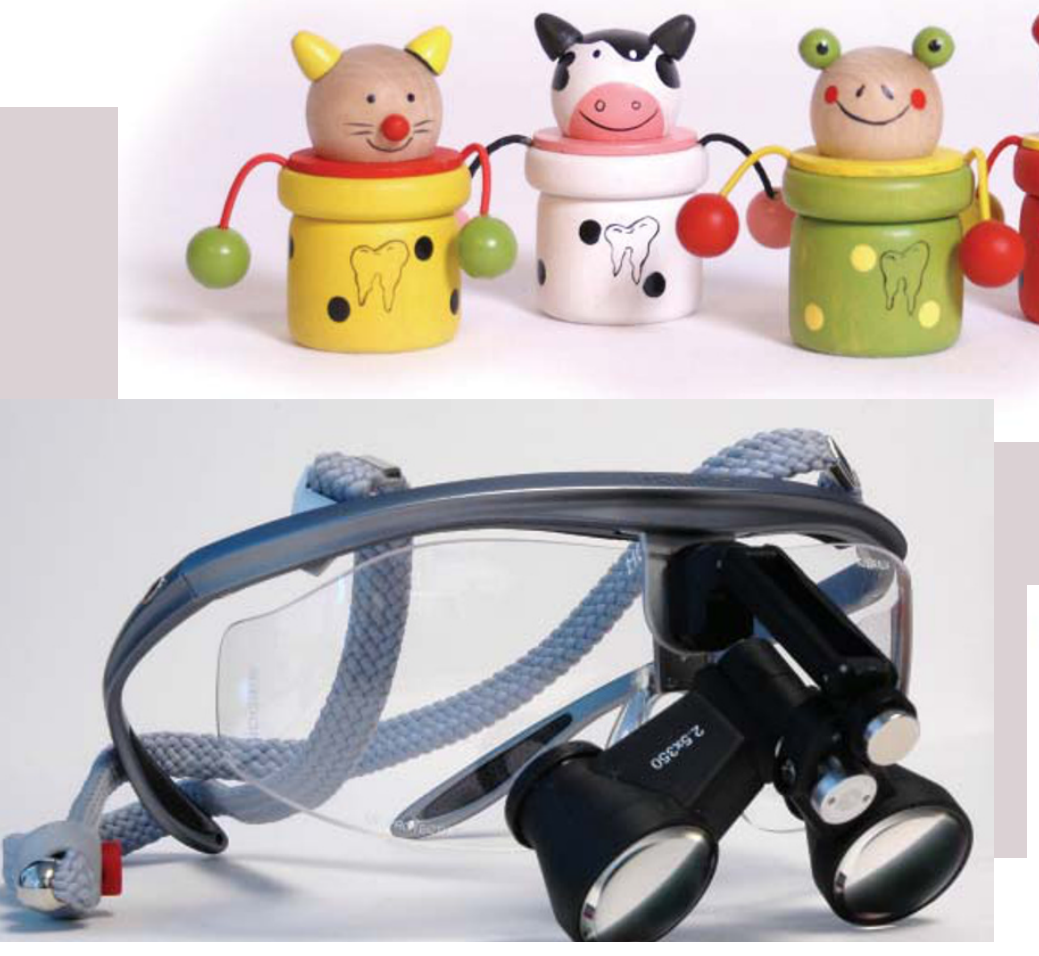

\section{LIGHTWEIGHT ADJUSTABLE LOUPES}

New MaximEyes Loupes, available from Blackwell Supplies, let you experience all the benefits of high quality magnification with a noticeable reduction in weight. The unique design reduces the weight of the loupes on the nose by $70 \%$, putting less strain on the wearer.

You can also adopt the most comfortable posture due to the multi-adjustment feature. This allows you to use MaximEyes Loupes without having to risk exposing yourself to the problems associated with bad posture.

For more information call John Jesshop of Blackwell Supplies on 02072241457 or fax 02072241694 .

\section{GENTLY DEEP CLEAN}

The Waterpik Dental Water Jet can help with a reduction in bleeding and gingivitis associated with periodontal infections, according to the manufacturers.

The Waterpik works with a combination of pulsation and pressure to clean where brushing and floss cannot reach. The biggest problem with periodontal pockets is daily cleaning, but using the Waterpik dental water jet with a Pik Pocket subgingival delivery tip will allow easy and gentle deep cleaning, even in $6 \mathrm{~mm}$ pockets.

For your professional courtesy discount on Waterpik Dental Water Jets speak to your dental wholesaler or for more information visit www. waterpik.co.uk. The product is also widely available in Boots stores.

\section{NEW HIGH RESISTANCE INSTRUMENTS}

Artio from Dentsply is the new range of instruments developed to accommodate the clinician with its ergonomically designed handle and excellent grip. The lightweight instruments have tips made from Ash CryoSteel, a cryogenically treated metal that is highly resistant to wear, for extra durability.

All of the instruments are colour-coded for specific uses, such as Burnishers and Pluggers in Aqua and Carvers in Orange Crush. Fifty pence from the sale of all Artio instruments will be donated to the Mouth Cancer Foundation.

For more information about the Dentsply range of dental products, call free on 0800 0723313.
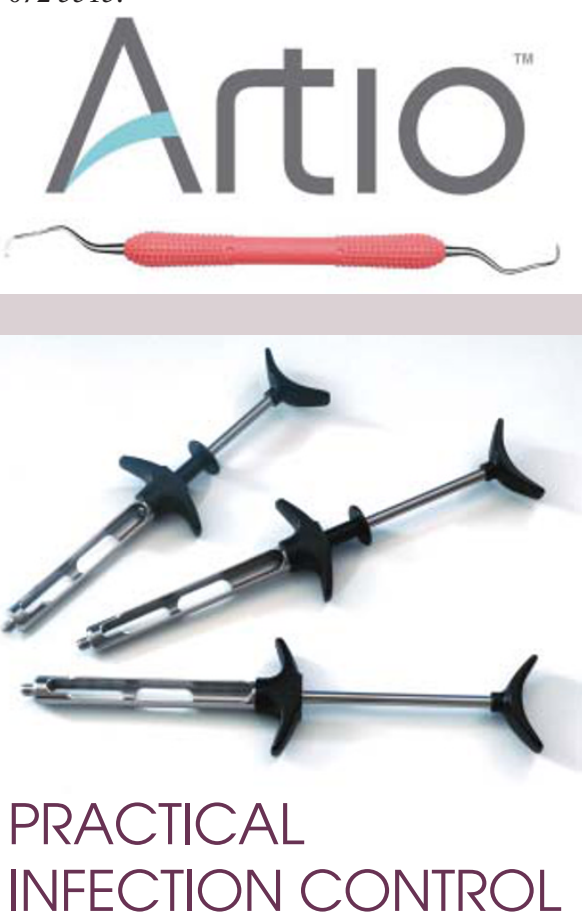

Infection control is a major issue within dental practices and there is demand for products that are not only robust but which can be cleaned effectively. The Rotor Syringe from Blackwell Supplies has been designed to provide a sensible, lightweight and successful solution.

The Rotor S/A Syringe is light and easy to use and has the advantage of being suitable for repeated autoclaving thanks to its rust resistant components. This makes it a practical and effective tool that can be used as part of a successful contamination control regime, helping to protect patients and staff from repeated infections. The syringe is constructed from quality stainless steel and moulded components from PEEK and eliminates the use of barbs, instead using the elasticity of the cartridge and thumb disk to induce controlled aspiration.

For further information call John Jesshop of Blackwell Supplies on 07971128077 or email: john.jesshop@blackwellsupplies.co.uk. 